\title{
Solubilization of Trans-Resveratrol in Some Mono-Solvents and Various Propylene Glycol + Water Mixtures
}

\author{
Mohammed Ghazwani ${ }^{1}$, Prawez Alam ${ }^{2}$, Mohammed H. Alqarni ${ }^{2}$, Hasan S. Yusufoglu ${ }^{2}$ and Faiyaz Shakeel ${ }^{3, * \mathbb{C}}$ \\ 1 Department of Pharmaceutics, College of Pharmacy, King Khalid University, Abha 61441, Saudi Arabia; \\ myghazwani@kku.edu.sa \\ 2 Department of Pharmacognosy, College of Pharmacy, Prince Sattam Bin Abdulaziz University, Al-Kharj \\ 11942, Saudi Arabia; prawez_pharma@yahoo.com (P.A.); m.alqarni@psau.edu.sa (M.H.A.); \\ h.yusufoglu@psau.edu.sa (H.S.Y.) \\ 3 Department of Pharmaceutics, College of Pharmacy, King Saud University, Riyadh 11451, Saudi Arabia \\ * Correspondence: faiyazs@fastmail.fm
}

check for updates

Citation: Ghazwani, M.; Alam, P.; Alqarni, M.H.; Yusufoglu, H.S.; Shakeel, F. Solubilization of Trans-Resveratrol in Some Mono-Solvents and Various Propylene Glycol + Water Mixtures. Molecules 2021, 26, 3091. https:// doi.org/10.3390/molecules26113091

Academic Editors: Piotr Cysewski, Tomasz Jeliński and Maciej Przybyłek

Received: 22 April 2021

Accepted: 20 May 2021

Published: 21 May 2021

Publisher's Note: MDPI stays neutral with regard to jurisdictional claims in published maps and institutional affiliations.

Copyright: (c) 2021 by the authors. Licensee MDPI, Basel, Switzerland. This article is an open access article distributed under the terms and conditions of the Creative Commons Attribution (CC BY) license (https:// creativecommons.org/licenses/by/ $4.0 /)$.

\begin{abstract}
This research deals with the determination of solubility, Hansen solubility parameters, dissolution properties, enthalpy-entropy compensation, and computational modeling of a naturallyderived bioactive compound trans-resveratrol (TRV) in water, methanol, ethanol, n-propanol, nbutanol, propylene glycol (PG), and various PG + water mixtures. The solubility of TRV in six different mono-solvents and various PG + water mixtures was determined at 298.2-318.2 K and $0.1 \mathrm{MPa}$. The measured experimental solubility values of TRV were regressed using six different computational/theoretical models, including van't Hoff, Apelblat, Buchowski-Ksiazczak $\lambda \mathrm{h}$, Yalkowsly-Roseman, Jouyban-Acree, and van't Hoff-Jouyban-Acree models, with average uncertainties of less than $3.0 \%$. The maxima of TRV solubility in mole fraction was obtained in neat PG $\left(2.62 \times 10^{-2}\right)$ at $318.2 \mathrm{~K}$. However, the minima of TRV solubility in the mole fraction was recorded in neat water $\left(3.12 \times 10^{-6}\right)$ at $298.2 \mathrm{~K}$. Thermodynamic calculation of TRV dissolution properties suggested an endothermic and entropy-driven dissolution of TRV in all studied mono-solvents and various PG + water mixtures. Solvation behavior evaluation indicated an enthalpy-driven mechanism as the main mechanism for TRV solvation. Based on these data and observations, PG has been chosen as the best mono-solvent for TRV solubilization.
\end{abstract}

Keywords: computational modeling; dissolution properties; Hansen solubility parameters; solubility; trans-resveratrol

\section{Introduction}

Trans-resveratrol (TRV) \{molecular structure: Figure 1; IUPAC name: 5-[(E)-2-(4hydroxyphenyl) ethenyl] benzene-1,3-diol; molecular formula: $\mathrm{C}_{14} \mathrm{H}_{12} \mathrm{O}_{3}$; molar mass: $228.24 \mathrm{~g} \mathrm{~mol}^{-1}$; PubChem CID: 445154, and CAS: 501-36-0]\} is a naturally-derived white crystalline powder [1,2]. It is isolated from various plant sources, such as peanuts, grapes, and berries [2,3]. TRV has shown multiple intracellular targeting properties [4]. Because of its multiple intracellular targeting properties, it has shown different therapeutic activities, such as antioxidant, cardiovascular, anti-inflammatory, neuroprotective, antidiabetic, and anticarcinogenic properties [5-11].

Nevertheless, its therapeutic effects are limited after oral administration because of its poor solubility in water, instability in physiological fluids, short plasma half-life, and extensive first-pass metabolism, despite its high permeability $[12,13]$.

Various formulation strategies, such as cyclodextrin complexation [14], polymeric microparticles [15], polymeric nanoparticles [16,17], nanosponges [18], nanostructured lipid carriers [19], polymeric micelles [20], self-emulsifying drug delivery systems [21,22], self-microemulsifying drug delivery systems [23], and nanosuspensions [24] have been 
studied and reported to enhance solubility, dissolution, and bioavailability of TRV. The solubility values of poorly water-soluble, naturally-derived bioactive compounds in various mono-solvents and cosolvent mixtures are important for research and development with respect to their purification, crystallization, isolation/extraction from different plant sources and formulation of final drug products $[1,2,25,26]$. The solubility of TRV in eleven mono-solvents, such as water, methanol, ethanol, 1-propanol, 2-propanol, 1-butanol, 1pentanol, 1-hexanol, ethyl acetate, and acetone at 278.2-318.2 $\mathrm{K}$ has been reported [27]. The solubility of TRV in various ethanol + water and acetone + water cosolvent mixtures at 273.2-323.2 $\mathrm{K}$ has also been reported [1]. The solubility of TRV in various transcutol + water cosolvent mixtures at 288.15-313.15 K has also been reported [28]. Recently, the solubility of TRV in various methanol + dichloromethane, ethanol + dichloromethane, n-propanol + dichloromethane, and n-butanol + dichloromethane cosolvent mixtures at 283.15-303.15 K has been reported [2]. The solubility of TRV in neat propylene glycol (PG) at $298.2 \mathrm{~K}$ and $310.2 \mathrm{~K}$ has also been found in the literature [22,23]. However, the solubility values, dissolution properties, and enthalpy-entropy compensation study of TRV in various PG + water mixtures have not yet been studied or reported. The vital role of PG in the solubilization of various poorly water-soluble compounds has been demonstrated well in previous studies [29-31].<smiles>Oc1ccc(/C=C/c2cc(O)cc(O)c2)cc1</smiles>

Figure 1. Molecular structure of trans-resveratrol (TRV).

Therefore, this research deals with the determination of solubility, Hansen solubility parameters, dissolution properties, and enthalpy-entropy compensation analysis of TRV in six mono-solvents (water, methanol, ethanol, n-propanol, n-butanol, and PG) and various PG + water mixtures at 298.2-318.2 K and laboratory atmopspheric pressure (0.1 MPa). The solubility data and other important physicochemical properties of TRV recorded in this work can be useful in the purification, crystallization, and isolation/extraction of TRV from different plant sources, as well as the formulation of final drug products.

\section{Results and Discussion}

\subsection{Experimental Solubility of TRV and Literature Comparison}

The generated experimental solubility $\left(x_{\mathrm{e}}\right)$ values of TRV in water, methanol, ethanol, n-propanol, n-butanol, and PG at 298.2-318.2 K and 0.1 MPa are presented in Table 1. The generated solubility values of TRV in various PG + water mixtures at 298.2-318.2 K and $0.1 \mathrm{MPa}$ are listed in Table 2.

The solubility of TRV in all studied mono-solvents at different temperatures has been reported [22-24]; however, the solubility and other important physicochemical parameters of TRV in various PG + water mixtures have not been reported. The mole fraction solubility of TRV in neat water at different temperatures has been reported well in the literature [1,27], and a comparison with the present experimental TRV solubility in neat water is presented in Figure 2. The experimental solubility of TRV in water was observed in good agreement with those reported in the literature [1,27]. The mole fraction solubility of TRV in neat ethanol at different temperatures has also been reported well in the literature $[1,2,27]$, 
and a comparison with the present experimental TRV solubility in neat ethanol is presented in Figure 3.

Table 1. Experimental solubilities $\left(x_{\mathrm{e}}\right)$ of trans-resveratrol (TRV) in the mole fraction in six different mono-solvents at 298.2-318.2 K and $0.1 \mathrm{MPa}^{\text {a }}$.

\begin{tabular}{cccccc}
\hline \multirow{2}{*}{ Components } & \multicolumn{5}{c}{$\boldsymbol{x}_{\mathbf{e}}$} \\
\cline { 2 - 6 } & $\mathbf{T = 2 9 8 . 2 ~ K}$ & $\boldsymbol{T}=\mathbf{3 0 3 . 2 ~ K}$ & $\boldsymbol{T}=\mathbf{3 0 8 . 2} \mathbf{K}$ & $\boldsymbol{T}=\mathbf{3 1 3 . 2} \mathbf{K}$ & $\mathbf{T = 3 1 8 . 2 ~ K}$ \\
\hline Water & $3.12 \times 10^{-6}$ & $4.00 \times 10^{-6}$ & $5.30 \times 10^{-6}$ & $6.35 \times 10^{-6}$ & $7.58 \times 10^{-6}$ \\
Methanol & $1.35 \times 10^{-2}$ & $1.46 \times 10^{-2}$ & $1.57 \times 10^{-2}$ & $1.68 \times 10^{-2}$ & $1.77 \times 10^{-2}$ \\
Ethanol & $1.66 \times 10^{-2}$ & $1.78 \times 10^{-2}$ & $1.95 \times 10^{-2}$ & $2.11 \times 10^{-2}$ & $2.30 \times 10^{-2}$ \\
n-Propanol & $1.11 \times 10^{-2}$ & $1.24 \times 10^{-2}$ & $1.32 \times 10^{-2}$ & $1.42 \times 10^{-2}$ & $1.55 \times 10^{-2}$ \\
n-Butanol & $8.37 \times 10^{-3}$ & $9.64 \times 10^{-3}$ & $1.06 \times 10^{-2}$ & $1.18 \times 10^{-2}$ & $1.28 \times 10^{-2}$ \\
PG & $1.73 \times 10^{-2}$ & $1.92 \times 10^{-2}$ & $2.08 \times 10^{-2}$ & $2.34 \times 10^{-2}$ & $2.62 \times 10^{-2}$ \\
\hline
\end{tabular}

a The relative uncertainties $u_{\mathrm{r}}$ are $u_{\mathrm{r}}(T)=0.010, u(p)=0.003$, and $u_{\mathrm{r}}\left(x_{\mathrm{e}}\right)=0.017$.

Table 2. The $x_{\mathrm{e}}$ values of TRV against mass fraction of propylene glycol (PG; $m$ ) in binary PG + water compositions at $298.2-318.2 \mathrm{~K}$ and $0.1 \mathrm{MPa}^{\mathrm{b}}$.

\begin{tabular}{cccccc}
\hline \multirow{5}{*}{$\boldsymbol{m}$} & $\boldsymbol{T}=\mathbf{x} \mathbf{x}$ \\
\cline { 2 - 6 } & $7.35 \times 10^{-6}$ & $9.40 \times 10^{-6}$ & $1.25 \times 10^{-5}$ & $1.50 \times 10^{-5}$ & $1.79 \times 10^{-5}$ \\
0.1 & $1.77 \times 10^{-5}$ & $2.24 \times 10^{-5}$ & $2.81 \times 10^{-5}$ & $3.32 \times 10^{-5}$ & $3.91 \times 10^{-5}$ \\
0.2 & $4.20 \times 10^{-5}$ & $5.12 \times 10^{-5}$ & $6.43 \times 10^{-5}$ & $7.50 \times 10^{-5}$ & $8.80 \times 10^{-5}$ \\
0.3 & $9.88 \times 10^{-5}$ & $1.23 \times 10^{-4}$ & $1.48 \times 10^{-4}$ & $1.77 \times 10^{-4}$ & $2.04 \times 10^{-4}$ \\
0.4 & $2.40 \times 10^{-4}$ & $2.81 \times 10^{-4}$ & $3.410 \times 10^{-4}$ & $3.96 \times 10^{-4}$ & $4.54 \times 10^{-4}$ \\
0.5 & $5.56 \times 10^{-4}$ & $6.55 \times 10^{-4}$ & $7.65 \times 10^{-4}$ & $8.87 \times 10^{-4}$ & $1.03 \times 10^{-3}$ \\
0.6 & $1.35 \times 10^{-3}$ & $1.54 \times 10^{-3}$ & $1.79 \times 10^{-3}$ & $2.03 \times 10^{-3}$ & $2.33 \times 10^{-3}$ \\
0.7 & $3.13 \times 10^{-3}$ & $3.57 \times 10^{-3}$ & $4.04 \times 10^{-3}$ & $4.58 \times 10^{-3}$ & $5.20 \times 10^{-3}$ \\
0.8 & $7.41 \times 10^{-3}$ & $8.30 \times 10^{-3}$ & $9.19 \times 10^{-3}$ & $1.05 \times 10^{-2}$ & $1.20 \times 10^{-2}$ \\
0.9 & &
\end{tabular}

b The relative uncertainties $u_{\mathrm{r}}$ are $u_{\mathrm{r}}(T)=0.013, u_{\mathrm{r}}(m)=0.010, u_{\mathrm{r}}(p)=0.003$ and $u_{\mathrm{r}}\left(x_{\mathrm{e}}\right)=0.020$.

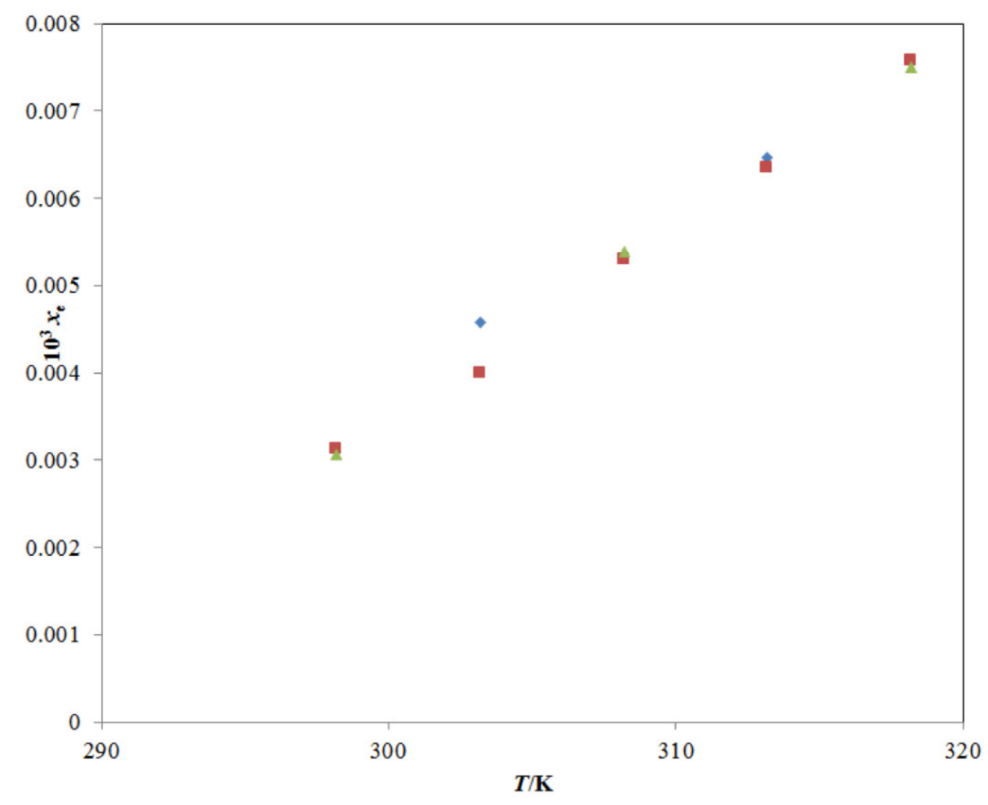

Figure 2. A graphical comparison of TRV solubility in neat water with reported values at different temperatures; the symbol $\square$ represents the experimental TRV solubility in neat water; the symbol represents the reported solubility values of TRV in neat water taken from reference [27]; the symbol $\Delta$ represents the reported solubility values of TRV in neat water taken from reference [1]. 


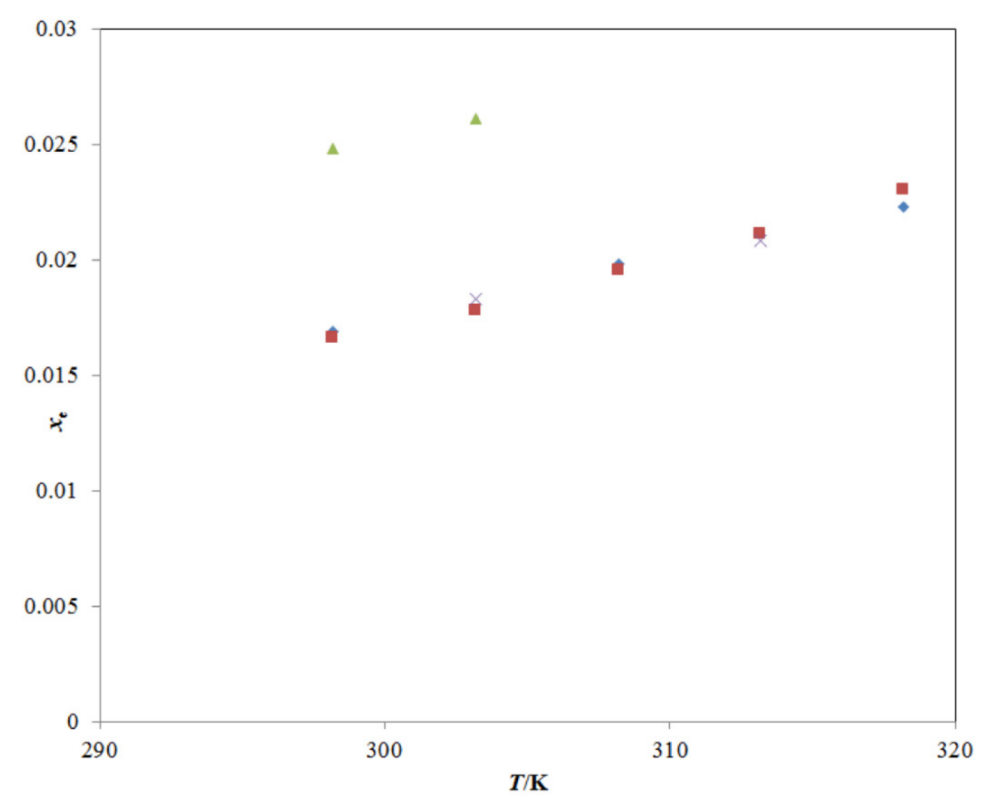

Figure 3. A graphical comparison of TRV solubility in neat ethanol with reported values at different temperatures; the symbol $\square$ represents the experimental TRV solubility in neat ethanol; the symbol represents the reported solubility values of TRV in neat ethanol taken from reference [27]; the symbol $\Delta$ represents the reported solubility values of TRV in neat ethanol taken from reference [1]; the symbol $\times$ represents the reported solubility values of TRV in neat ethanol taken from reference [2].

The experimental solubility of TRV in neat ethanol agreed with those reported by Sun et al. [1,27]; however, it deviated significantly from those reported by Ha et al. [2]. The mole fraction solubility of TRV in neat methanol, neat n-propanol, and neat n-butanol at different temperatures has also been reported in the literature [2,27], and a comparison with the present experimental TRV solubility in the same is presented in Figure 4A-C. The experimental solubility of TRV in neat methanol, neat n-propanol, and neat n-butanol also agreed with those reported by Sun et al. [27]; however, it deviated significantly from those reported by Ha et al. [2]. The saturated solubility of TRV in PG was reported as 63.96 $\mathrm{mg} \mathrm{mL}^{-1}$ (converted to $2.16 \times 10^{-2}$ in mole fraction) at $310.2 \mathrm{~K}$ by Tang et al. [23]. The saturated solubility of TRV in PG was reported as $9.22 \mathrm{mg} \mathrm{mL}^{-1}$ (converted to $3.18 \times 10^{-3}$ in mole fraction) at $298.2 \mathrm{~K}$ by Balata et al. [22]. The mole fraction solubility of TRV in PG at 310.2 K was not measured in this study. The mole fraction solubility of TRV in PG at 310.2 $\mathrm{K}$ was obtained from the interpolation of the graph plotted between $\ln x_{\mathrm{e}}$ and $1 / T$ and determined as $2.13 \times 10^{-2}$, which was much closer to those reported by Tang et al. [23]. In this work, the mole fraction solubility of TRV in PG at $298.2 \mathrm{~K}$ was $1.73 \times 10^{-2}$, which deviated from those reported by Balata et al. [22]. Overall, the experimental solubilities of TRV agreed with those reported by Sun et al. and Tang et al. $[1,23,27]$ and deviated from those reported by Ha et al. and Balata et al. [2,22]. The differences in TRV solubilities might be due to differences in analytical methods, equilibrium time, rotational speeds, and other experimental conditions.

In general, it was observed that the $x_{\mathrm{e}}$ values of TRV enhanced significantly with an increase in temperature in the mono-solvents and PG + water mixtures $(p<0.05)$ and were in accordance with previous studies [25-27]. Among the mono-solvents, the $x_{\mathrm{e}}$ values of TRV at $318.2 \mathrm{~K}$ were maximal in PG $\left(2.62 \times 10^{-2}\right)$, followed by ethanol $\left(2.30 \times 10^{-2}\right)$, methanol $\left(1.77 \times 10^{-2}\right)$, n-propanol $\left(1.55 \times 10^{-2}\right)$, n-butanol $\left(1.25 \times 10^{-2}\right)$, and water $\left(7.58 \times 10^{-6}\right)$. Similar data were also noted at $298.2 \mathrm{~K}, 303.2 \mathrm{~K}, 308.2 \mathrm{~K}$, and $313.2 \mathrm{~K}$. The solubility of TRV in all studied alcohols was of a similar magnitude at all temperatures studied $(p>0.05)$. In addition, the TRV solubility in the alcohols was significantly high compared to its solubility in water $(p<0.05)$. The solubility of the solute in different mono-solvents depends on the dynamics and polarity of the mono-solvents. The differ- 
ent solubility values of TRV in different mono-solvents were possible due to differences in the dynamics and polarity of the solvents [32]. The high solubility of TRV in alcohols was possible due to high intermolecular interactions between TRV and studied alcoholic mono-solvents compared to the intramolecular interactions between TRV-TRV and solventsolvent molecules. Among different mono-solvents studied, the maximum TRV solubility was recorded in PG. Therefore, PG has been considered as the best mono-solvent for TRV solubilization. The maximum solubility of TRV in PG was possible due to higher intermolecular interactions between TRV and PG compared to those that occurred between TRV and other alcohols.

Among the PG + water mixtures, the $x_{\mathrm{e}}$ values of TRV were recorded at a maximum of PG mass fraction $(m)=0.9$. Overall, TRV was soluble in all studied alcoholic mono-solvents and practically insoluble in water. The effect of the PG $m$ value on the logarithmic solubility of TRV was also studied at different temperatures, and the results are shown in Figure 5. The logarithmic solubility of TRV increased significantly with an increase in the PG mass fraction $(p<0.05)$.
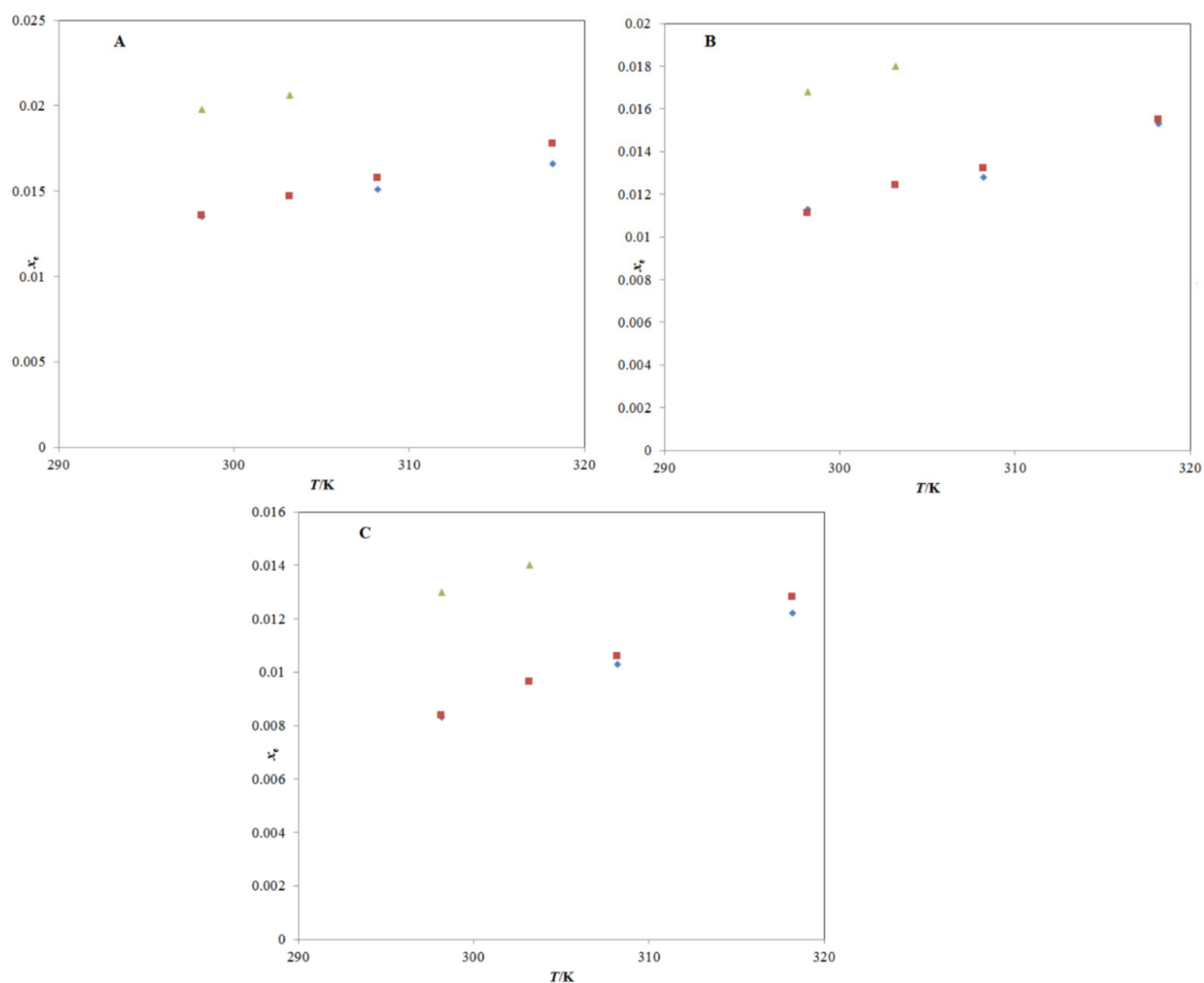

Figure 4. A graphical comparison of TRV solubility in (A) neat methanol, (B) neat n-propanol, and (C) neat n-butanol with its reported values at different temperatures; the symbol $\square$ represents the experimental solubility of TRV in (A) neat methanol, (B) neat n-propanol, and (C) neat n-butanol; the symbol represents the reported solubility values of TRV in (A) neat methanol, (B) neat n-propanol, and (C) neat n-butanol taken from reference [27]; the symbol $\mathbf{A}$ represents the reported solubility values of TRV in (A) neat methanol, (B) neat n-propanol, and (C) neat n-butanol taken from reference [2]. 


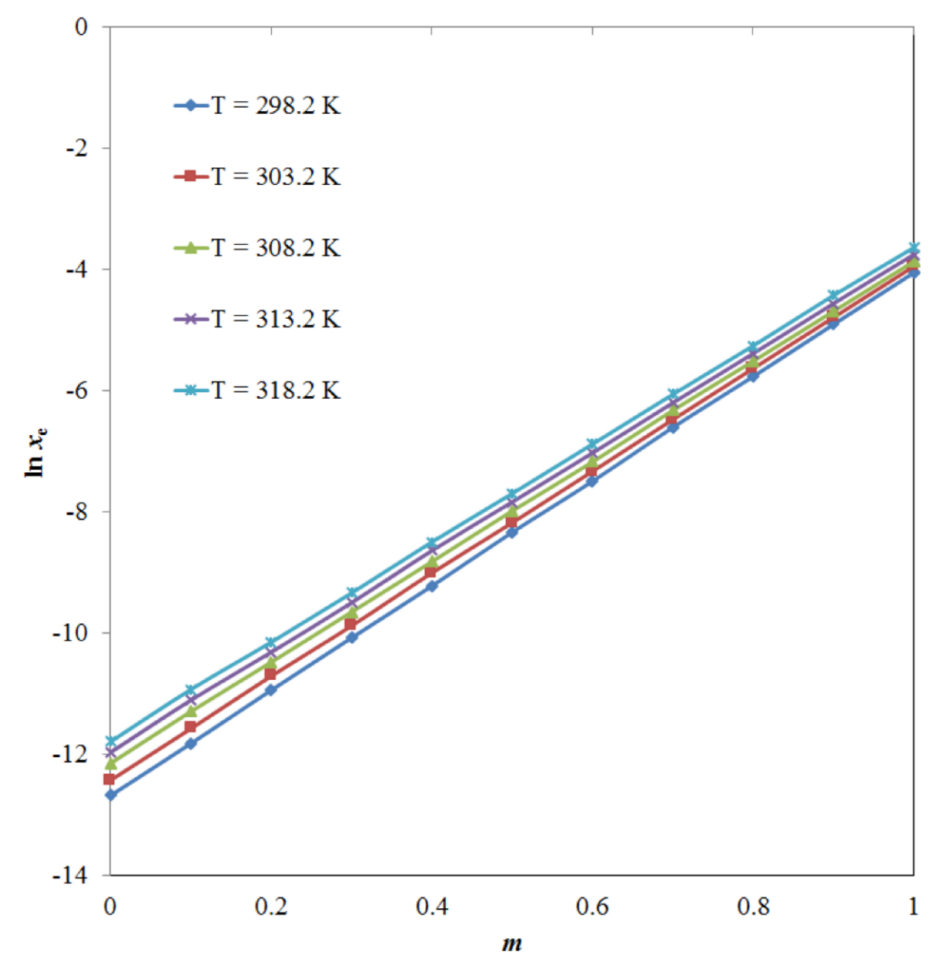

Figure 5. The effect of the propylene glycol (PG) mass fraction $(m)$ on logarithmic solubility $\left(\ln x_{\mathrm{e}}\right)$ values of TRV at five different temperatures.

\subsection{Determination of Hansen Solubility Parameters (HSPs)}

The HSPs are important for the validation of experimental solubility data in order to find out the best solvent for the solubilization of materials. Therefore, different HSPs for TRV and the six mono-solvents were determined by the HSPiP software, and their predicted values are presented in Table 3 . The TRV total HSP $(\delta)$ value was $27.10 \mathrm{MPa}^{1 / 2}$, indicating that TRV had a medium polarity. Some of the alcoholic mono-solvents, such as methanol $\left(\delta=30.30 \mathrm{MPa}^{1 / 2}\right)$, ethanol $\left(\delta=25.40 \mathrm{MPa}^{1 / 2}\right)$, and PG $\left(\delta=29.20 \mathrm{MPa}^{1 / 2}\right)$, had a $\delta$ value close to that of TRV and hence were suitable for TRV solubilization. The $\delta$ value for water was $47.80 \mathrm{MPa}^{1 / 2}$, indicating that water is a highly polar mono-solvent and not suitable for TRV solubilization. The HSPs for various PG + water mixtures free of TRV $\left(\delta_{\text {mix }}\right)$ are listed in Table S1. The $\delta_{\text {mix }}$ values for various PG + water mixtures free of TRV were $31.06-45.94 \mathrm{MPa}^{1 / 2}$. The TRV $\delta$ value $\left(27.10 \mathrm{MPa}^{1 / 2}\right)$ was closer to $m=0.9$ of PG $\left(\delta_{\text {mix }}=31.06 \mathrm{MPa}^{1 / 2}\right)$ in the PG + water mixtures, compared to other cosolvent mixtures studied. The maximum TRV experimental solubility was also obtained at $m=0.9$ of PG in the PG + water mixtures. The calculated values of the Krevelen-Hoftyzer solubility parameter $(\Delta \bar{\delta})$, the three-dimensional solubility parameter space $\left(R_{\mathrm{a}}\right)$, and Greenhalgh's solubility parameter $(\Delta \delta)$ are also listed in Table 3. It was found that the miscibility between the solute and mono-solvent is maximal if $\Delta \bar{\delta}$ is smaller than $5.0 \mathrm{MPa}^{1 / 2}[33,34]$. The $\Delta \bar{\delta}$ in water $\left(\Delta \bar{\delta}=28.26 \mathrm{MPa}^{1 / 2}\right)$ and methanol $\left(\Delta \bar{\delta}=7.96 \mathrm{MPa}^{1 / 2}\right)$ was $\geq 5.0 \mathrm{MPa}^{1 / 2}$, suggesting the immiscibility/insolubility of TRV in water and methanol, according to this concept. However, the $\Delta \bar{\delta}$ in ethanol $\left(\Delta \bar{\delta}=4.84 \mathrm{MPa}^{1 / 2}\right)$, n-propanol $\left(\Delta \bar{\delta}=4.76 \mathrm{MPa}^{1 / 2}\right)$, n-butanol $\left(\Delta \bar{\delta}=4.85 \mathrm{MPa}^{1 / 2}\right)$, and PG $\left(\Delta \bar{\delta}=6.86 \mathrm{MPa}^{1 / 2}\right)$ was much closer to $<5.0 \mathrm{MPa}^{1 / 2}$, indicating the solubility/miscibility of TRV in ethanol, n-propanol, n-butanol, and PG, according to this concept. It was also reported that the solubility between the solute and mono-solvent is maximal if $R_{\mathrm{a}}$ is smaller than $5.6 \mathrm{MPa}^{1 / 2}[34,35]$. The $R_{\mathrm{a}}$ was higher in all mono-solvents, suggesting the insolubility of TRV in all mono-solvents, according to this concept. The solubility between the solute and mono-solvent is maximal if $\Delta \delta$ is smaller than $7.0 \mathrm{MPa}^{1 / 2}$. The $\Delta \delta$ value was maximal in water $\left(\Delta \delta=20.70 \mathrm{MPa}^{1 / 2}\right)$, suggesting the insolubility of TRV in water. However, the $\Delta \delta$ was lower in methanol $\left(\Delta \delta=3.20 \mathrm{MPa}^{1 / 2}\right)$, 
ethanol $\left(\Delta \delta=1.70 \mathrm{MPa}^{1 / 2}\right)$, n-propanol $\left(\Delta \delta=4.20 \mathrm{MPa}^{1 / 2}\right)$, n-butanol $\left(\Delta \delta=4.20 \mathrm{MPa}^{1 / 2}\right)$, and PG $\left(\Delta \delta=2.10 \mathrm{MPa}^{1 / 2}\right)$, suggesting the miscibility of TRV in all these mono-solvents, according to this concept [36]. Overall, methanol, ethanol, and PG were suitable for TRV solubilization.

Table 3. Various solubility parameters of TRV and six different mono-solvents at $298.2 \mathrm{~K}$.

\begin{tabular}{|c|c|c|c|c|c|c|c|}
\hline \multirow{2}{*}{ Components } & \multicolumn{4}{|c|}{ Hansen Solubility Parameters } & \multirow[t]{2}{*}{$R_{\mathrm{a}}{ }^{*} / \mathrm{MPa}^{1 / 2}$} & \multirow[t]{2}{*}{$\Delta \bar{\delta} / \mathrm{MPa}^{1 / 2}$} & \multirow[t]{2}{*}{$\Delta \delta * / \mathrm{MPa}^{1 / 2}$} \\
\hline & $\delta_{\mathrm{d}} / \mathrm{MPa}^{1 / 2}$ & $\delta_{\mathrm{p}} / \mathrm{MPa}^{1 / 2}$ & $\delta_{\mathrm{h}} / \mathrm{MPa}^{1 / 2}$ & $\delta / \mathbf{M P a}^{1 / 2}$ & & & \\
\hline TRV & 20.60 & 7.30 & 15.90 & 27.10 & - & - & - \\
\hline Water & 15.50 & 16.00 & 42.30 & 47.80 & 29.60 & 28.26 & 20.70 \\
\hline Methanol & 17.40 & 10.60 & 22.40 & 30.30 & 9.70 & 7.96 & 3.20 \\
\hline Ethanol & 16.20 & 8.40 & 17.60 & 25.40 & 9.02 & 4.84 & 1.70 \\
\hline n-Propanol & 16.00 & 7.00 & 14.70 & 22.90 & 9.28 & 4.76 & 4.20 \\
\hline n-Butanol & 15.90 & 6.30 & 15.20 & 22.90 & 9.47 & 4.85 & 4.20 \\
\hline PG & 17.40 & 9.10 & 21.70 & 29.20 & 8.82 & 6.86 & 2.10 \\
\hline
\end{tabular}

* These values were calculated between TRV and respective mono-solvents.

\subsection{Computational/Theoretical Models}

The generated TRV solubility data was fitted with van't Hoff, modified Apelblat, Buchowski-Ksiazczak $\lambda$ h, Yalkowsky-Roseman, Jouyban-Acree, and Jouyban-Acree-van't Hoff models [37-45]. The results of the graphical fitting between the $x_{\mathrm{e}}$ and the modified Apelblat solubility $\left(x^{\mathrm{Apl}}\right)$ data of TRV in the mono-solvents as a function of $1 / T$ are shown in Figure 6, which presents a good fitting between the $x_{\mathrm{e}}$ and $x^{\mathrm{Apl}}$ data of TRV in all six mono-solvents. The results for the modified Apelblat model fitting are shown in Table 4. The root mean square deviations (RMSDs) for TRV in the mono-solvents were estimated as $0.41 \%-1.71 \%$, with an average $R M S D$ of $0.89 \%$. The TRV determination coefficient $\left(R^{2}\right)$ in the mono-solvents was predicted as 0.9935-0.9999. The results of the graphical fitting between the $x_{\mathrm{e}}$ and $x^{\mathrm{Apl}}$ values of TRV in the PG + water mixtures as a function of $1 / T$ for the modified Apelblat model are shown in Figure 7, which also shows a good curve fitting. The results for the modified Apelblat model fitting of TRV in the PG + water mixtures are shown in Table 5. The RMSDs for TRV in the PG + water mixtures were estimated as $0.25 \%-1.87 \%$, with an average $R M S D$ of $0.93 \%$. The TRV $R^{2}$ in the PG + water mixtures was predicted as $0.9971-0.9999$. These data and observations showed a good correlation of experimental solubility values of TRV in the mono-solvents and PG + water mixtures with the modified Apelblat model.

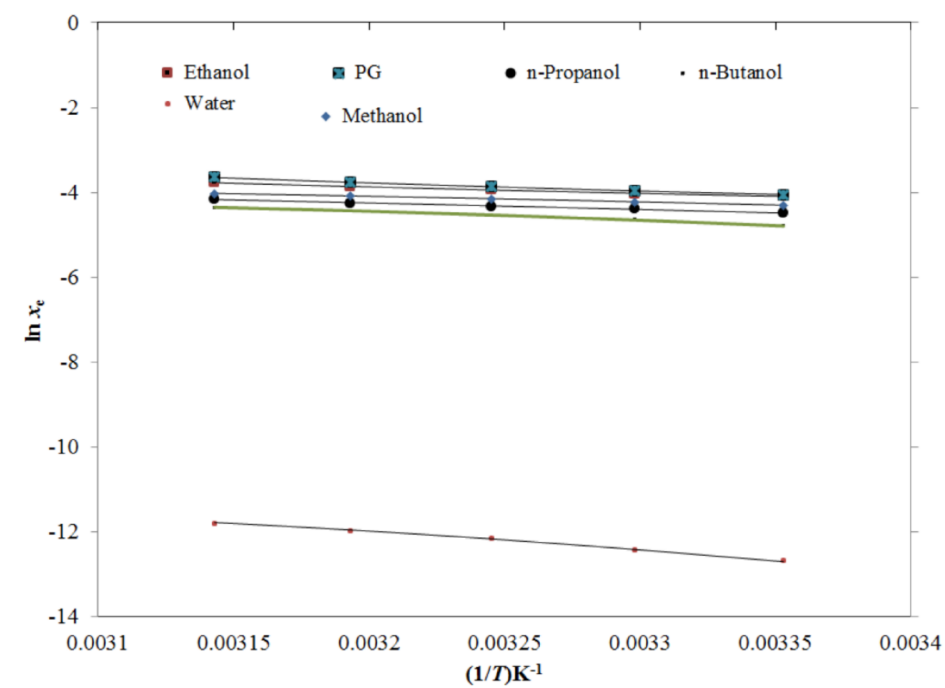

Figure 6. The correlation of $\ln x_{\mathrm{e}}$ values of TRV with the modified Apelblat model in six different mono-solvents as a function of $1 / T$; symbols represent the experimental solubilities of TRV, and solid lines represent the solubilities of TRV calculated using the modified Apelblat model. 
Table 4. The results of the Apelblat model for TRV in six different mono-solvents.

\begin{tabular}{ccccccc}
\hline Components & $\boldsymbol{A}$ & $\boldsymbol{B}$ & $\boldsymbol{C}$ & $\boldsymbol{R}^{\mathbf{2}}$ & $\boldsymbol{R} M S D(\%)$ & Overall RMSD (\%) \\
\hline Water & 762.67 & -39195 & -113.01 & 0.9969 & 1.71 & \\
Methanol & 152.42 & -8288.9 & -22.620 & 0.9999 & 0.41 & 0.89 \\
Ethanol & -186.16 & 7036.6 & 27.810 & 0.9989 & 0.51 & \\
n-Propanol & 79.710 & -5141.1 & -11.750 & 0.9935 & 0.93 & \\
n-Butanol & 412.24 & -20850 & -60.920 & 0.9990 & 0.91 & \\
PG & -287.67 & 11366 & 43.080 & 0.9974 & 0.87 & \\
\hline
\end{tabular}

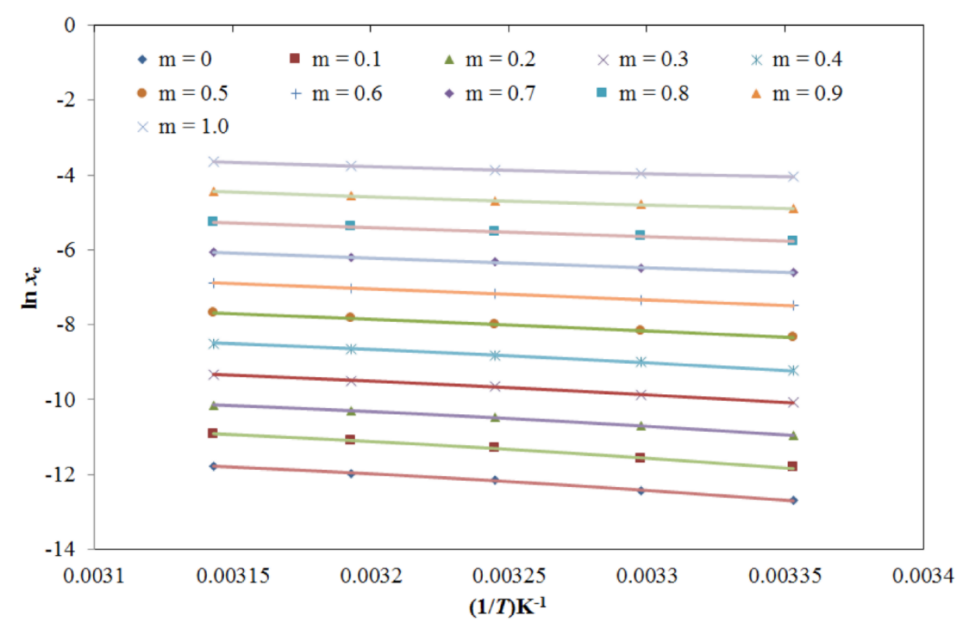

Figure 7. The correlation of $\ln x_{\mathrm{e}}$ values of TRV with the modified Apelblat model in various PG + water compositions as a function of $1 / T$; symbols represent the experimental solubilities of TRV, and solid lines represent the solubilities of TRV calculated using the modified Apelblat model.

Table 5. The results of the Apelblat model for TRV in various PG + water compositions.

\begin{tabular}{|c|c|c|c|c|c|c|}
\hline$m$ & $A$ & $B$ & $C$ & $R^{2}$ & RMSD (\%) & Overall RMSD (\%) \\
\hline 0.1 & 718.95 & -37178 & -106.37 & 0.9971 & 1.87 & \\
\hline 0.2 & 629.72 & -32599 & -93.250 & 0.9986 & 1.11 & \\
\hline 0.3 & 409.21 & -22250.4 & -60.490 & 0.9977 & 1.36 & \\
\hline 0.4 & 488.56 & -25784 & -72.190 & 0.9999 & 0.87 & \\
\hline 0.5 & 166.97 & -10657 & -24.490 & 0.9981 & 1.02 & 0.93 \\
\hline 0.6 & 45.190 & -4886.7 & -6.3700 & 0.9999 & 0.25 & \\
\hline 0.7 & -122.25 & 3109.0 & 18.460 & 0.9993 & 0.61 & \\
\hline 0.8 & -82.530 & 1488.6 & 12.590 & 0.9998 & 0.47 & \\
\hline 0.9 & -368.28 & 14764 & 55.080 & 0.9989 & 0.87 & \\
\hline
\end{tabular}

The results for the graphical fitting between the $x_{\mathrm{e}}$ and van't Hoff model solubility $\left(x^{\text {van't }}\right)$ values of TRV in the mono-solvents as a function of $1 / T$ for the van't Hoff model are shown in Figure S1, which shows a good curve fitting. The resulting data for the van't Hoff model fitting of TRV in the mono-solvents are listed in Table 6. The RMSDs for TRV in the mono-solvents were $0.52 \%-2.67 \%$, with an average $R M S D$ of $1.35 \%$. The TRV $R^{2}$ in the mono-solvents was predicted as 0.9928-0.9980. The results for the graphical fitting between $x_{\mathrm{e}}$ and $x^{\mathrm{van} t \mathrm{t}}$ values of TRV in the PG + water mixtures as a function of $1 / T$ for the van't Hoff model are shown in Figure S2, which also shows a good correlation. 
Table 6. The results of the van't Hoff model for TRV in six different mono-solvents.

\begin{tabular}{cccccc}
\hline Components & $\boldsymbol{a}$ & $\boldsymbol{b}$ & $\boldsymbol{R}^{\mathbf{2}}$ & $\boldsymbol{R} M S D(\%)$ & Overall RMSD (\%) \\
\hline Water & 1.6000 & -4252.1 & 0.9928 & 2.67 & \\
Methanol & 0.03000 & -1290.8 & 0.9980 & 0.52 & 1.35 \\
Ethanol & 1.1000 & -1553.8 & 0.9969 & 1.04 & \\
n-Propanol & 0.55000 & -1503.3 & 0.9931 & 1.20 & \\
n-Butanol & 1.9800 & -2014.7 & 0.9933 & 1.47 & \\
PG & 2.4500 & -1943.0 & 0.9940 & 1.23 & \\
\hline
\end{tabular}

The resulting data for the van't Hoff model fitting of TRV in the PG + water mixtures are summarized in Table 7. The RMSDs for TRV in the PG + water mixtures were $0.53 \%-2.65 \%$, with an average RMSD of $1.41 \%$. The TRV $R^{2}$ in the PG + water mixtures was predicted as $0.9935-1.0000$. These data and observations again showed a good correlation of experimental solubility data of TRV in the mono-solvents and PG + water mixtures with the van't Hoff model.

Table 7. The results of the van't Hoff model for TRV in various PG + water compositions.

\begin{tabular}{|c|c|c|c|c|c|}
\hline$m$ & $a$ & $b$ & $R^{2}$ & RMSD (\%) & Overall RMSD (\%) \\
\hline 0.1 & 2.5700 & -4286.5 & 0.9935 & 2.65 & \\
\hline 0.2 & 1.7000 & -3764.3 & 0.9950 & 1.98 & \\
\hline 0.3 & 1.8000 & -3541.2 & 0.9961 & 1.76 & \\
\hline 0.4 & 2.3900 & -3460.7 & 0.9973 & 1.67 & \\
\hline 0.5 & 1.9700 & -3075.0 & 0.9979 & 1.28 & 1.41 \\
\hline 0.6 & 2.2500 & -2907.0 & 1.0000 & 0.59 & \\
\hline 0.7 & 2.0700 & -2589.4 & 0.9990 & 0.53 & \\
\hline 0.8 & 2.2600 & -2396.0 & 0.9996 & 0.71 & \\
\hline 0.9 & 2.6300 & -2252.4 & 0.9949 & 1.54 & \\
\hline
\end{tabular}

The resulting data for the Buchowski-Ksiazczak $\lambda h$ model fitting of TRV in the monosolvents are summarized in Table 8. The RMSDs for TRV in the mono-solvents were estimated as $1.71 \%-3.14 \%$, with an average $R M S D$ of $2.37 \%$.

Table 8. The results of the Buchowski-Ksiazczak $\lambda h$ model for TRV in six different mono-solvents.

\begin{tabular}{ccccc}
\hline $\boldsymbol{m}$ & $\boldsymbol{\lambda}$ & $\boldsymbol{h}$ & RMSD (\%) & Overall $R$ MSD (\%) \\
\hline Water & 5.2900 & 802.97 & 3.14 & \\
Methanol & 1.3600 & 946.05 & 1.71 & 2.37 \\
Ethanol & 0.77000 & 1979.1 & 2.12 & \\
n-Propanol & 1.2300 & 1217.9 & 2.24 & \\
n-Butanol & 0.75000 & 2673.7 & 2.58 & \\
PG & 0.15000 & 12666 & 2.47 & \\
\hline
\end{tabular}

The resulting data for the Buchowski-Ksiazczak $\lambda h$ model fitting of TRV in the PG + water mixtures are listed in Table 9. The RMSDs for TRV in the PG + water mixtures were estimated as $0.74 \%-3.84 \%$, with an average $R M S D$ of $2.22 \%$. These data and observations showed a good correlation of experimental solubility data of TRV in the mono-solvents and PG + water mixtures with the Buchowski-Ksiazczak $\lambda h$ model. 
Table 9. The results of the Buchowski-Ksiazczak $\lambda h$ model for TRV in various PG + water compositions.

\begin{tabular}{ccccc}
\hline Samples & $\lambda$ & $\boldsymbol{h}$ & $\boldsymbol{R} M S D(\%)$ & Overall RMSD (\%) \\
\hline 0.1 & 4.3800 & 976.58 & 3.84 & \\
0.2 & 4.2800 & 877.56 & 3.12 & 2.22 \\
0.3 & 3.7700 & 939.26 & 2.82 & \\
0.4 & 3.0200 & 1142.4 & 2.74 & \\
0.5 & 2.7300 & 1124.4 & 2.42 & \\
0.6 & 2.1400 & 1356.0 & 1.04 & \\
0.7 & 1.7300 & 1491.5 & 0.74 & \\
0.8 & 1.1800 & 2025.0 & 2.95 & \\
0.9 & 0.54000 & 4126.0 & & \\
\hline
\end{tabular}

The resulting data for the Yalkowsky-Roseman model fitting of TRV in the PG + water mixtures are listed in Table 10. The RMSDs for the Yalkowsky-Roseman model were estimated as $0.90 \%-3.06 \%$, with an average $R M S D$ of $1.86 \%$.

Table 10. $\log x^{\text {Yal }}$ values of TRV calculated using the Yalkowsky-Roseman model in various PG + water compositions at 298.2-318.2 K.

\begin{tabular}{llllllll}
\hline $\boldsymbol{m}$ & \multicolumn{5}{c}{$\log \boldsymbol{x}^{\text {Yal }}$} & \multirow{2}{*}{ RMSD (\%) } & Overall RMSD (\%) \\
\cline { 2 - 6 } & $\mathbf{2 9 8 . 1 5}$ & $\mathbf{3 0 3 . 1 5}$ & $\mathbf{3 0 8 . 1 5}$ & $\mathbf{3 1 3 . 1 5}$ & $\mathbf{3 1 8 . 1 5}$ & & \\
\hline 0.1 & -5.13 & -5.02 & -4.91 & -4.84 & -4.76 & 3.06 & \\
0.2 & -4.75 & -4.66 & -4.55 & -4.48 & -4.41 & 1.55 & \\
0.3 & -4.38 & -4.29 & -4.19 & -4.12 & -4.05 & 0.90 & \\
0.4 & -4.00 & -3.92 & -3.83 & -3.77 & -3.70 & 2.80 & \\
0.5 & -3.63 & -3.55 & -3.47 & -3.41 & -3.35 & 2.21 & \\
0.6 & -3.25 & -3.18 & -3.11 & -3.05 & -2.99 & 1.20 & \\
0.7 & -2.88 & -2.81 & -2.75 & -2.70 & -2.64 & 2.29 & \\
0.8 & -2.50 & -2.45 & -2.39 & -2.34 & -2.28 & 1.10 & \\
0.9 & -2.13 & -2.08 & -2.03 & -1.98 & -1.93 & 1.69 & \\
\hline
\end{tabular}

The resulting data for the Jouyban-Acree and Jouyban-Acree-van't Hoff model fittings of TRV in the PG + water mixtures are listed in Table 11. An overall RMSD for the Jouyban-Acree model was predicted as $0.82 \%$; however, an overall RMSD for the Jouyban-Acree-van't Hoff model was predicted as $0.96 \%$. Generally, all six theoretical models performed well in the solubility correlation of TRV.

Table 11. The results of the Jouyban-Acree and Jouyban-Acree-van't Hoff models for TRV in PG + water mixtures.

\begin{tabular}{ccc}
\hline System & Jouyban-Acree & Jouyban-Acree-Van't Hoff \\
\hline & & $A_{1} 2.45$ \\
PG + water & $J_{\mathrm{i}} 83.20$ & $B_{1}-1943.00$ \\
& & $A_{2} 1.60$ \\
RMSD $(\%)$ & 0.82 & $B_{2}-4252.10$ \\
& & $J_{\mathrm{i}} 78.65$ \\
\hline
\end{tabular}

\subsection{Dissolution Properties}

Three different apparent thermodynamic quantities, including apparent standard enthalpy $\left(\Delta_{\text {sol }} H^{0}\right)$, apparent standard Gibbs energy $\left(\Delta_{\text {sol }} G^{0}\right)$, and apparent standard entropy $\left(\Delta_{\text {sol }} S^{0}\right)$, were determined to evaluate the dissolution properties of TRV. For the determination of these quantities, only the ideality of the solution was considered, and therefore, these qualities are called apparent thermodynamic quantities. The values of $\Delta_{\text {sol }} H^{0}$ for 
TRV in the mono-solvents and PG + water mixtures were determined from the van't Hoff graphs. The van't Hoff plots for the determination of the $\Delta_{\text {sol }} H^{0}$ values for TRV in the mono-solvents are shown in Figure S3; however, the van't Hoff plots for the determination of the $\Delta_{\mathrm{sol}} H^{0}$ values for TRV in the PG + water mixtures are displayed in Figure S4. The resulting values of different thermodynamic parameters for TRV in the mono-solvents are portrayed in Table 12.

Table 12. Apparent thermodynamic parameters $\left(\Delta_{\mathrm{sol}} H^{0}, \Delta_{\mathrm{sol}} G^{0}\right.$, and $\left.\Delta_{\mathrm{sol}} S^{0}\right)$ and $R^{2}$ values for TRV in six different mono-solvents ${ }^{\mathrm{c}}$.

\begin{tabular}{ccccc}
\hline Components & $\boldsymbol{\Delta}_{\text {sol }} \boldsymbol{H}^{\mathbf{0}} / \mathbf{k J ~} \mathbf{~ m o l}^{-\mathbf{1}}$ & $\boldsymbol{\Delta}_{\text {sol }} G^{\mathbf{0}} / \mathbf{k J ~} \mathbf{~ m o l}^{-\mathbf{1}}$ & $\boldsymbol{\Delta}_{\text {sol }} \boldsymbol{S}^{\mathbf{0}} / \mathbf{J ~} \mathbf{~ m o l}^{-\mathbf{1}} \mathbf{K}^{-\mathbf{1}}$ & $\boldsymbol{R}^{\mathbf{2}}$ \\
\hline Water & 35.39 & 31.24 & 13.47 & 0.9927 \\
Methanol & 10.74 & 10.64 & 0.32 & 0.9939 \\
Ethanol & 12.93 & 10.07 & 9.27 & 0.9970 \\
n-Propanol & 12.51 & 11.06 & 4.69 & 0.9930 \\
n-Butanol & 16.77 & 11.65 & 16.60 & 0.9931 \\
PG & 16.17 & 9.86 & 20.49 & 0.9941 \\
\hline
\end{tabular}

${ }^{\mathrm{c}}$ The average relative uncertainties are $u_{\mathrm{r}}\left(\Delta_{\text {sol }} H^{0}\right)=0.52, u_{\mathrm{r}}\left(\Delta_{\mathrm{sol}} G^{0}\right)=0.59$, and $u_{\mathrm{r}}\left(\Delta_{\mathrm{sol}} S^{0}\right)=0.69$; these uncertainties are relative standard deviations of all values of each thermodynamic quantity.

The $\Delta_{\mathrm{sol}} H$ values for TRV in the mono-solvents were estimated as $10.74-35.39 \mathrm{~kJ} \mathrm{~mol}^{-1}$. The values of $\Delta_{\mathrm{sol}} G^{0}$ for TRV in the mono-solvents were estimated as 9.86-31.24 kJ mol${ }^{-1}$. The $\Delta_{\text {sol }} G^{0}$ for TRV was minimal in PG and maximal in water, which may be because of the maximum and minimum solubility of TRV in PG and water, respectively. The recorded positive values of $\Delta_{\mathrm{sol}} H^{0}$ for TRV indicated an endothermic dissolution of TRV in all six mono-solvents [29,37]. The values of $\Delta_{\text {sol }} S^{0}$ for TRV in the mono-solvents were also determined as positive values, in the range of $0.32-20.49 \mathrm{~J} \mathrm{~mol}^{-1} \mathrm{~K}^{-1}$, indicating an entropydriven dissolution of TRV in all six mono-solvents [29]. The resulting data for the dissolution properties of TRV in the PG + water mixtures are portrayed in Table 13.

Table 13. Apparent thermodynamic quantities $\left(\Delta_{\mathrm{sol}} H^{0}, \Delta_{\mathrm{sol}} G^{0}\right.$, and $\left.\Delta_{\mathrm{sol}} S^{0}\right)$ and $R^{2}$ values for TRV in various $P G+$ water compositions ${ }^{\mathrm{d}}$.

\begin{tabular}{cccccccccc}
\hline Parameters & $\boldsymbol{m}=\mathbf{0 . 1}$ & $\boldsymbol{m}=\mathbf{0 . 2}$ & $\boldsymbol{m}=\mathbf{0 . 3}$ & $\boldsymbol{m}=\mathbf{0 . 4}$ & $\boldsymbol{m}=\mathbf{0 . 5}$ & $\boldsymbol{m}=\mathbf{0 . 6}$ & $\boldsymbol{m}=\mathbf{0 . 7}$ & $\boldsymbol{m}=\mathbf{0 . 8}$ & $\boldsymbol{m}=\mathbf{0 . 9}$ \\
\hline$\Delta_{\text {sol }} H^{0} / \mathrm{kJ} \mathrm{mol}^{-1}$ & 35.68 & 31.33 & 29.48 & 28.81 & 25.60 & 24.20 & 21.55 & 19.94 & 18.75 \\
$\Delta_{\text {sol }} G^{0} / \mathrm{kJ} \mathrm{mol}^{-1}$ & 29.04 & 26.93 & 24.81 & 22.62 & 20.50 & 18.39 & 16.21 & 14.11 & 11.97 \\
$\Delta_{\text {sol }} S^{0} / \mathrm{J} \mathrm{mol}^{-1} \mathrm{~K}^{-1}$ & 21.53 & 14.29 & 15.15 & 20.07 & 16.55 & 18.86 & 17.33 & 18.94 & 22.02 \\
$R^{2}$ & 0.9934 & 0.9948 & 0.9960 & 0.9972 & 0.9979 & 0.9999 & 0.9991 & 0.9997 & 0.9951 \\
\hline
\end{tabular}

d The average relative uncertainties are $u_{\mathrm{r}}\left(\Delta_{\mathrm{sol}} H^{0}\right)=0.21, u_{\mathrm{r}}\left(\Delta_{\mathrm{sol}} G^{0}\right)=0.28$, and $u_{\mathrm{r}}\left(\Delta_{\mathrm{sol}} S^{0}\right)=0.14$; these uncertainties are relative standard deviations of all values of each thermodynamic quantity.

The $\Delta_{\mathrm{sol}} H$ values for TRV in the PG + water mixtures were estimated as 18.75-35.68 kJ mol ${ }^{-1}$. The $\Delta_{\mathrm{sol}} G^{0}$ values for TRV in the PG + water mixtures were estimated as $11.97-29.04 \mathrm{~kJ} \mathrm{~mol}^{-1}$. The recorded positive values of $\Delta_{\mathrm{sol}} H^{0}$ for TRV also suggested an endothermic dissolution of TRV in the PG + water mixtures $[25,26]$. The $\Delta_{\mathrm{sol}} S^{0}$ values for TRV in the PG + water mixtures were estimated as $14.29-22.02 \mathrm{~J} \mathrm{~mol}^{-1} \mathrm{~K}^{-1}$, indicating an entropy-driven dissolution of TRV in PG + water mixtures [25]. Based on all these observations and results, the dissolution of TRV was observed as endothermic and entropy-driven in the mono-solvents and PG + water mixtures $[25,26,29,37]$.

\subsection{Enthalpy-Entropy Compensation Evaluation}

The enthalpy-entropy compensation analysis is a much-debated phenomenon, which is being applied in the evaluation of thermodynamic analysis of drugs/pharmaceuticals, proteins, ligands, and nucleic acids [46,47]. It has been thoroughly evaluated using both experimental and theoretical approaches in order to understand the molecular recognition and drug design $[47,48]$. Therefore, enthalpy-entropy compensation analysis was applied in this work to evaluate the solvation behavior/cosolvent mechanism for TRV 
in the PG + water mixtures. The results of the enthalpy-entropy compensation analysis are displayed in Figure 8. TRV in all PG + water mixtures and mono-solvents (PG and water) presented a linear $\Delta_{\mathrm{sol}} H^{\circ}$ vs. $\Delta_{\mathrm{sol}} G^{\circ}$ graph with a positive slope value greater than unity and an $R^{2}$ value greater than 0.99 . Based on these observations, the driving mechanism for TRV solvation is proposed as enthalpy-driven in all PG + water mixtures, including mono-solvents (PG and water). The enthalpy-driven mechanism for TRV was possible because of the higher solvation of TRV in PG molecules compared to its solvation in water molecules $[49,50]$. It is well-known that water helps in determining the stability, structure, dynamics, and functions of hydrophilic as well as hydrophobic molecules [51]. In this work, TRV/water solvation was much weaker than TRV/PG solvation. This observation was due to the fact that the intermolecular interactions between TRV-PG molecules were higher compared to the intramolecular interactions between TRV-TRV and water-water molecules. The recorded solvation behavior of TRV in the PG + water mixtures was similar to those proposed for the solvation behavior of vanillin and sulfacetamide in various PG + water mixtures $[29,31]$.

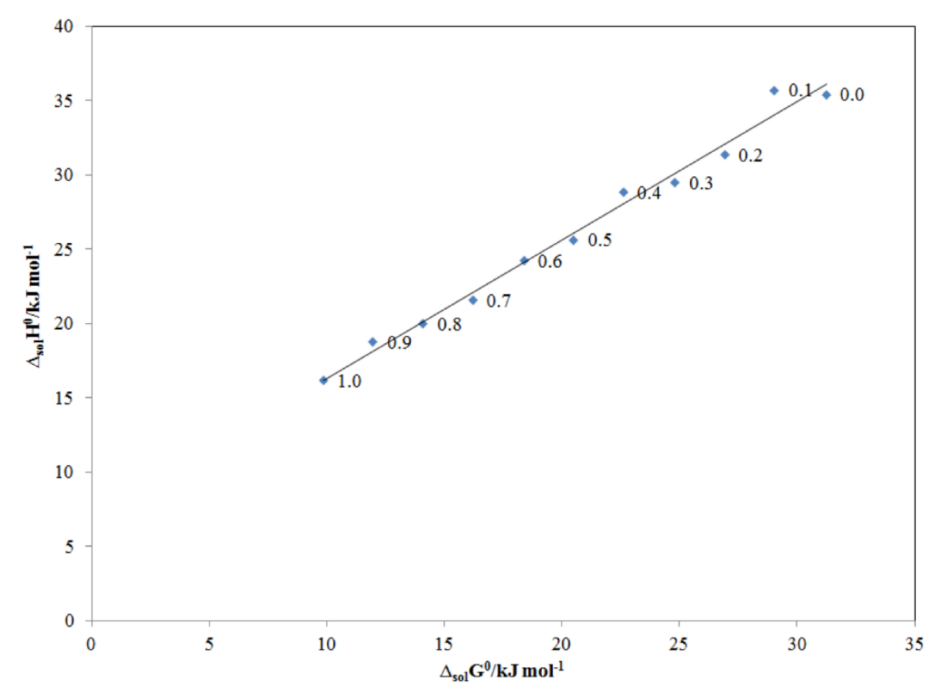

Figure 8. $\Delta_{\text {sol }} H^{0}$ vs. $\Delta_{\text {sol }} G^{0}$ enthalpy-entropy compensation plot for the solubility of TRV in various PG + water compositions at $T_{\mathrm{hm}}=308 \mathrm{~K}$.

\section{Materials and Methods}

\subsection{Materials}

TRV (mass fraction purity $=0.993$ ) was obtained from Sigma-Aldrich (St. Louis, MO, USA). The mono-solvents of analytical grades, such as methanol, ethanol, n-propanol, and n-butanol, were obtained from Alfa Aesar (Ward Hill, MA, USA). PG of analytical grade was obtained from E-Merck (Darmstadt, Germany). The chromatography grade/deionized water (specific conductivity $<1.0 \mu \mathrm{S} \mathrm{cm}^{-1}$ and $\mathrm{pH}$ 6.7) was obtained from an ELGA water purifier (ELGA, Wycombe, UK). Further purification was not performed because all materials were of high purity. The details of the TRV and mono-solvents, such as source, molecular formula, molar mass, purification method, method of analysis, and the CAS number, are summarized in Supplementary Table S2.

\subsection{Preparation of $P G+$ Water Solvent Mixtures}

All PG + water solvent mixtures were obtained on a mass basis, using a Digital Analytical Balance (Mettler Toledo, Greifensee, Switzerland) with a sensitivity of $\pm 0.10 \mathrm{mg}$. The mass fraction of PG for different PG + water solvent mixtures was obtained, varied by 0.10, from 0.10-0.90. Each PG + water solvent mixture was obtained in triplicate. 


\subsection{Measurement of TRV Solubility}

The TRV solubility in water, methanol, ethanol, n-propanol, n-butanol, PG, and binary PG + water mixtures was measured using a shake flask technique at 298.2-318.2 K and $0.1 \mathrm{MPa}$ [52]. The same experimental conditions were applied as those explained in our previous studies [26,29]. The amount of TRV in equilibrium samples of six different monosolvents and various PG + water mixtures was determined by a reported high-performance liquid chromatography (HPLC) method at $306 \mathrm{~nm}$ [53]. The ternary mixture of methanol: $10 \mathrm{mM}$ potassium dihydrogen phosphate buffer $(\mathrm{pH} 6.8)$ : acetonitrile $(63: 30: 7, v / v / v)$ was utilized as the mobile phase for HPLC determination of TRV. The amount of TRV $\left(\mu \mathrm{g} \mathrm{g}^{-1}\right.$ ) was obtained using a TRV calibration curve. The $x_{\mathrm{e}}$ value of TRV in the monosolvents and PG + water mixtures were calculated using their standard equations, reported previously $[26,29]$.

\subsection{Determination of HSPS}

The HSPs are generally employed to estimate the miscibility of solute in a monosolvent or cosolvent mixtures. Hansen had separated total HSP $(\delta)$ into three contributions, including hydrogen bonding $\left(\delta_{\mathrm{h}}\right)$, dipole interactions $\left(\delta_{\mathrm{p}}\right)$, and non-polar interactions $\left(\delta_{\mathrm{d}}\right)$. It has been generally assumed that if the HSP of solute and mono-solvent/ solvent mixtures are similar, it will give the maximum solubility $[54,55]$. Therefore, various HSPs for TRV, water, methanol, ethanol, n-propanol, n-butanol, PG, and various PG + water mixtures free of TRV were calculated in this work, using Equation (1) [36-38]:

$$
\delta^{2}=\delta_{\mathrm{d}}^{2}+\delta_{\mathrm{p}}^{2}+\delta_{\mathrm{h}}^{2}
$$

The values of $\delta, \delta_{\mathrm{d}}, \delta_{\mathrm{p}}$, and $\delta_{\mathrm{h}}$ for TRV and various mono-solvents were obtained using HSPiP software (version 4.1.07, Louisville, KY, USA) by putting the simplified molecularinput line-entry system (SMILES) of TRV and six different mono-solvents. The SMILES for each component were taken directly from the PubChem database.

The HSPs for different PG + water mixtures $\left(\delta_{\text {mix }}\right)$ free of TRV were determined using Equation (2) [54]:

$$
\delta_{\text {mix }}=\propto \delta_{1}+(1-\propto) \delta_{2}
$$

where $\alpha$ is the PG volume fraction in PG + water mixtures; $\delta_{1}$ is the PG HSP; $\delta_{2}$ is the water HSP.

The Van Krevelen-Hoftyzer method confirmed the miscibility of solute and solvent using the $\Delta \bar{\delta}$. The $\Delta \bar{\delta}$ between TRV and a specific mono-solvent was determined using Equation $(3)[33,55]$ :

$$
\Delta \bar{\delta}=\left(\delta_{\mathrm{d} 2}^{2}-\delta_{\mathrm{d} 1}^{2}\right)+\left(\delta_{\mathrm{p} 2}^{2}-\delta_{\mathrm{p} 1}^{2}\right)+\left(\delta_{\mathrm{h} 2}^{2}-\delta_{\mathrm{h} 1}^{2}\right)^{1 / 2}
$$

where subscripts 1 and 2 refer to the specific mono-solvent and TRV, respectively. It was evidenced that the maximum solubility/miscibility between the solute and mono-solvent is attained if $\Delta \bar{\delta}$ is smaller than $5.0 \mathrm{MPa}^{1 / 2}[37,55]$. The $R_{\mathrm{a}}$ between TRV and the mono-solvent was determined using Equation (4) [34,56]:

$$
\mathrm{Ra}^{2}=4\left(\delta_{\mathrm{d} 2}-\delta_{\mathrm{d} 1}\right)^{2}+\left(\delta_{\mathrm{p} 2}-\delta_{\mathrm{p} 1}\right)^{2}+\left(\delta_{\mathrm{h} 2}-\delta_{\mathrm{h} 1}\right)^{2}
$$

Based on $R_{\mathrm{a}}$ data, the maximum solubility between the solute and mono-solvent can be attained if $R_{\mathrm{a}}$ is smaller than $5.6 \mathrm{MPa}^{1 / 2}$ [34,37]. However, higher $R_{\mathrm{a}}$ values correspond to poor solubility between the solute and mono-solvent.

The $\Delta \delta$ between TRV and the mono-solvent was obtained using Equation (5) [36]:

$$
\Delta \delta=\delta_{2}-\delta_{1}
$$

where subscripts 1 and 2 refer to the specific mono-solvent and TRV, respectively. According to this theory, the solute and mono-solvent are miscible if $\Delta \delta$ is smaller than $7.0 \mathrm{MPa}^{1 / 2}$, 
whereas the combination of the solute and mono-solvent is immiscible if $\Delta \delta$ is greater than $10.0 \mathrm{MPa}^{1 / 2}[36]$.

\subsection{Computational/Theoretical Models}

The generated TRV solubility data in six mono-solvents and various PG + water mixtures were fitted using six theoretical models. The TRV solubility in the six monosolvents was fitted using van't Hoff, modified Apelblat, and Buchowski-Ksiazczak $\lambda h$ models [37-41], while the TRV solubility in various PG + water mixtures were fitted with van't Hoff, modified Apelblat, Buchowski-Ksiazazak $\lambda h$, Yalkowsky-Roseman, JouybanAcree, and Jouyban-Acree-van't Hoff models [37-45]. The $x^{\mathrm{Apl}}$ of TRV in the monosolvents and mixtures was determined using Equation (6) $[38,39]$ :

$$
\ln x^{\mathrm{Apl}}=A+\frac{B}{T}+C \ln (T)
$$

where, $A, B$, and $C$ are the coefficients of Equation (6), which were predicted using nonlinear multivariate regression analysis of the TRV experimental solubilities included in Table 1 for the mono-solvents and Table 2 for the PG + water mixtures [37]. The fitting between $x_{\mathrm{e}}$ and $x^{\mathrm{Apl}}$ of TRV was carried out in terms of RMSD and $R^{2}$. The RMSD was obtained using its standard formula reported in the literature $[26,29]$.

The $x^{\text {van't }}$ of TRV in the mono-solvents and PG + water mixtures was calculated using Equation (7) [37]:

$$
\ln x^{\mathrm{van}^{\prime} \mathrm{t}}=a+\frac{b}{T}
$$

where, $a$ and $b$ are the parameters of the Equation (7). These parameters were obtained by the method of least squares [25].

The Buchowski-Ksiazczak $\lambda h$ model solubility $(x)$ of TRV was calculated using Equation (8) [40,41]:

$$
\ln \left[1+\frac{\lambda(1-x)}{x}\right]=\lambda h\left[\frac{1}{T}-\frac{1}{T_{\text {fus }}}\right]
$$

where $\lambda$ and $h$ are the parameters of Equation (8).

The logarithmic solubility of the Yalkowsky-Roseman model $\left(\log x^{\text {Yal }}\right)$ for TRV in various PG + water mixtures was calculated using Equation (9) [42]:

$$
\log x^{\text {Yal }}=m_{1} \log x_{1}+m_{2} \log x_{2}
$$

where $x_{1}$ is the solubility of TRV in PG; $x_{2}$ is the solubility of TRV in water; $m_{1}$ is the PG mass fraction; $m_{2}$ is the water mass fraction.

The Jouyban-Acree model solubility $\left(x_{\mathrm{m}, \mathrm{T}}\right)$ for TRV in various PG + water mixtures was calculated by Equation (10) [43-45]:

$$
\ln x_{\mathrm{m}, \mathrm{T}}=m_{1} \ln x_{1}+m_{2} \ln x_{2}+\left[\frac{m_{1} m_{2}}{T} \sum_{i=0}^{2} J_{\mathrm{i}}\left(m_{1}-m_{2}\right)\right]
$$

where $J_{\mathrm{i}}$ is the model parameter of Equation (10), which was obtained by applying nointercept regression analysis [43,57].

The Jouyban-Acree-van't Hoff model solubility $\left(x_{\mathrm{m}, \mathrm{T}}\right)$ for TRV in various PG + water mixtures was calculated by Equation (11) [58,59]:

$$
\ln x_{\mathrm{m}, \mathrm{T}}=m_{1}\left(A_{1}+\frac{B_{1}}{T}\right)+m_{2}\left(A_{2}+\frac{B_{2}}{T}\right)+\left[\frac{m_{1} m_{2}}{T} \sum_{i=0}^{2} J_{\mathrm{i}}\left(m_{1}-m_{2}\right)\right]
$$

where $A_{1}, B_{1}, A_{2}, B_{2}$, and $J_{i}$ are the parameters of Equation (11). 


\subsection{Dissolution Properties}

For the evaluation of dissolution properties of TRV in the mono-solvents and PG + water mixtures, apparent thermodynamic analysis was conducted. Three thermodynamic parameters for TRV dissolution properties- $\Delta_{\mathrm{sol}} H^{0}, \Delta_{\mathrm{sol}} G^{0}$, and $\Delta_{\text {sol }} S^{0}$-were determined [6062]. The well-known van't Hoff equation was employed to determine the $\Delta_{\text {sol }} H^{0}$ values for TRV in the mono-solvents and PG + water mixtures using Equation (12) [60,61]:

$$
\left(\frac{\partial \ln x_{\mathrm{e}}}{\partial\left(\frac{1}{T}-\frac{1}{T_{\mathrm{hm}}}\right)}\right)_{P}=-\frac{\Delta_{\mathrm{sol}} H^{0}}{R}
$$

where $T_{\mathrm{hm}}$ is the mean harmonic temperature and was determined as $308 \mathrm{~K}$. By plotting $\ln$ $x_{\mathrm{e}}$ values of TRV vs. $\frac{1}{T}-\frac{1}{T_{\mathrm{hm}}}$, the $\Delta_{\mathrm{sol}} H^{0}$, and $\Delta_{\mathrm{sol}} G^{0}$ values for TRV were obtained from the slope and intercept, respectively, using Equations (13) and (14), respectively [60,61]:

$$
\begin{gathered}
\Delta_{\mathrm{sol}} H^{0}=-R\left(\frac{\partial \ln x_{\mathrm{e}}}{\partial\left(\frac{1}{T}-\frac{1}{T_{\mathrm{hm}}}\right)}\right)_{P} \\
\Delta_{\mathrm{sol}} G^{0}=-R T_{\mathrm{hm}} \times \text { intercept }
\end{gathered}
$$

The $\Delta_{\mathrm{sol}} S^{0}$ values for TRV in the mono-solvents and PG + water mixtures were calculated using Equation (15) [60-62]:

$$
\Delta_{\mathrm{sol}} S^{0}=\frac{\Delta_{\mathrm{sol}} H^{0}-\Delta_{\mathrm{sol}} G^{0}}{T_{\mathrm{hm}}}
$$

\subsection{Enthalpy-Entropy Compensation Evaluation}

The solvation behavior of TRV in the PG + water mixtures was evaluated using an enthalpy-entropy compensation analysis, detailed in previous studies $[49,50]$. This analysis was performed by plotting the weighted graphs of $\Delta_{\mathrm{sol}} H^{\circ}$ and $\Delta_{\mathrm{sol}} G^{\circ}$ at $T_{\mathrm{hm}}=308 \mathrm{~K}$ [49].

\subsection{Statistical Evaluation}

Statistical evaluation was conducted by adopting the Kruskal-Wallis analysis followed by Denn's test, using GraphpadInstat software (Version 9.1.1, San Diego, CA, USA). A $p$-value of less than 0.05 was taken as significant.

\section{Conclusions}

This study deals with the evaluation of solubility, HSPs, dissolution properties, enthalpy-entropy compensation, and computational modeling of a naturally-derived bioactive compound TRV in water, methanol, ethanol, n-propanol, n-butanol, PG, and various PG + water mixtures. Various HSPs were estimated to select the best mono-solvent for TRV solubility. TRV experimental solubility values were correlated well with van't Hoff, modified Apelblat, Buchowski-Ksiazczak $\lambda h$, Yalkowsky-Roseman, Jouyban-Acree, and Jouyban-Acree-van't Hoff models. The TRV solubility was enhanced significantly with increased temperature $(p<0.05)$ in water, methanol, ethanol, n-propanol, n-butanol, PG, and various PG + water mixtures. The TRV solubility was maximal in PG, followed by ethanol, methanol, n-propanol, n-butanol, and water, at each temperature studied. Dissolution studies portrayed an endothermic and entropy-driven dissolution of TRV in water, methanol, ethanol, n-propanol, n-butanol, PG, and various PG + water mixtures. The enthalpy-entropy compensation evaluation suggested an enthalpy-driven mechanism as the main mechanism for TRV solvation. Based on all these data and observations, PG is the best mono-solvent for the solubilization of TRV. 
Supplementary Materials: The following are available online, Figure S1: Correlation of $\ln x_{\mathrm{e}}$ values of TRV with the van't Hoff model in six different mono-solvents as a function of $1 / T$; symbols represent the experimental solubilities of TRV, and solid lines represent the solubilities of TRV calculated using the van't Hoff model, Figure S2: The correlation of $\ln x_{\mathrm{e}}$ values of TRV with the van't Hoff model in various PG + water compositions as a function of $1 / T$; symbols represent the experimental solubilities of TRV, and solid lines represent the solubilities of TRV calculated using the van't Hoff model, Figure S3: van't Hoff plots for TRV plotted between $\ln x_{\mathrm{e}}$ and $1 / T-1 / T_{\mathrm{hm}}$ for TRV in six different mono-solvents, Figure S4: van't Hoff plots for TRV plotted between $\ln x_{\mathrm{e}}$ and $1 / T-1 / T_{\mathrm{hm}}$ for TRV in various PG + water mixtures, Table S1: Hansen solubility parameters $\left(\delta_{\text {mix }} / \mathrm{MPa}^{1 / 2}\right)$ for various PG + water mixtures free of TRV at $298.2 \mathrm{~K}$, Table S2: Details information about materials used.

Author Contributions: Conceptualization, M.G. and F.S.; methodology, M.H.A. and P.A.; software, F.S. and H.S.Y.; validation, M.G., F.S., H.S.Y. and P.A.; formal analysis, M.H.A.; investigation, F.S., M.H.A. and M.G.; resources, M.G.; data curation, H.S.Y.; writing-original draft preparation, F.S.; writing-review and editing, M.G., P.A., M.H.A. and H.S.Y.; visualization, P.A.; supervision, F.S.; project administration, M.G.; funding acquisition, M.G. All authors have read and agreed to the published version of the manuscript.

Funding: This research was funded by the Deanship of Scientific Research (DSR) at King Khalid University, Abha, Saudi Arabia, through the General Research Project under the grant number (G.R.P-250-42) and The APC was funded by DSR.

Institutional Review Board Statement: Not applicable.

Informed Consent Statement: Not applicable.

Data Availability Statement: All data associated with this article are included in Supplementary Materials.

Acknowledgments: The authors extend their appreciation to the Deanship of Scientific Research at King Khalid University for funding this work through the General Research Project under the grant number (G.R.P-250-42).

Conflicts of Interest: The authors declare no conflict of interest.

Sample Availability: Samples of the compounds TRV are available from the authors.

\section{References}

1. Sun, X.; Shao, Y.; Yan, W. Measurement and correlation of solubilities of trans-resveratrol in ethanol + water and acetone + water mixed solvents at different temperatures. J. Chem. Eng. Data 2008, 53, 2562-2566. [CrossRef]

2. Ha, E.S.; Park, H.; Lee, S.K.; Sim, W.Y.; Jiong, J.S.; Kim, M.S. Equilibrium solubility and modeling of trans-resveratrol in dichloromethane and primary alcohol solvent mixtures at different temperatures. J. Mol. Liq. 2020, 311, 113363. [CrossRef]

3. Babu, S.K.; Kumar, K.V.; Subbaraju, G.V. Estimation of trans-resveratrol in herbal extracts and dosage forms by high-performance thin-layer chromatography. Chem. Pharm. Bull. 2005, 53, 691-693. [CrossRef] [PubMed]

4. Lee, K.W.; Bode, A.M.; Dong, Z. Molecular targets of phytochemicals for cancer prevention. Nat. Rev. Cancer 2011, 11, 211-218. [CrossRef]

5. Gulcin, I. Antioxidant properties of resveratrol: A structure-activity insight. Innov. Food Sci. Emerg. Technol. 2010, 11, 210-218. [CrossRef]

6. Zhou, Z.X.; Mou, S.F.; Chen, X.Q.; Gong, L.L.; Ge, W.S. Anti-inflammatory activity of resveratrol prevents inflammation by inhibiting NF-kB in animal models of acute pharyngitis. Mol. Med. Rep. 2018, 7, 1269-1274.

7. Jang, M.; Cai, L.; Udeani, G.O.; Slowing, K.V.; Thomas, C.F.; Beecher, C.W.W.; Fong, H.H.S.; Farnsworth, N.R.; Kinghorn, A.D.; Mehta, R.G.; et al. Cancer chemopreventive activity of resveratrol a natural product derived from grapes. Science 1997, 275, 218-220.

8. Park, C.S.; Lee, Y.C.; Kim, J.D.; Kim, C.H. Inhibitory effects of Polygonum cuspidatum water extract (PCWE) and its component resveratrol [correction of rasveratrol] on acyl-coenzyme A-cholesterol acyltransferase activity for cholesteryl ester synthesis in HepG2 cells. Vasc. Pharmacol. 2004, 40, 279-284. [CrossRef] [PubMed]

9. Cote, B.; Carlson, L.J.; Rao, D.A.; Alani, A.W.G. Combination of resveratrol and quercetin polymeric micelles mitigates doxorubicin induced cardiotoxicity in vitro and in vivo. J. Control. Release 2015, 213, 128-133. [CrossRef] [PubMed]

10. Rao, Y.L.; Ganaraja, B.; Joy, T.; Pai, M.M.; Ullal, S.D.; Murlimanju, B.V. Neuroprotective effects of resveratrol in Alzheimer's disease. Front. Biosci. 2020, 12, 130-149.

11. Ramírez-Garza, S.L.; Laveriano-Santos, E.P.; Marhuenda-Muñoz, M.; Storniolo, C.E.; Tresserra-Rimbau, A.; Vallverdú-Queralt, A.; LamuelaRaventós, R.M. Health effects of resveratrol: Results from human intervention trials. Nutrients 2018, 10, 1892. [CrossRef] [PubMed] 
12. Marier, J.F.; Vachon, P.; Gritsas, A.; Zhang, J.; Moreau, J.P.; Ducharme, M.P. Metabolism and disposition of resveratrol in rats: Extent of absorption, glucuronidation, and enterohepatic recirculation evidenced by a linked-rat model. J. Pharmacol. Exp. Ther. 2002, 302, 369-373. [CrossRef] [PubMed]

13. Walle, T. Bioavailability of resveratrol. Ann. N. Y. Acad. Sci. 2011, 1215, 9-15. [CrossRef] [PubMed]

14. Catenacci, L.; Sorrenti, M.; Bonferoni, M.C.; Hunt, L.; Caira, M.R. Inclusion of the phytoalexin trans-resveratrol in cyclodextrins: A thermal, spectroscopic, and X-ray structural study. Molecules 2020, 25, 998. [CrossRef] [PubMed]

15. Gartziandia, O.; Lasa, A.; Pedraz, J.L.; Miranda, J.; Portillo, M.P.; Igartua, M.; Hernández, R.M. Preparation and characterization of resveratrol loaded pectin/alginate blend gastro-resistant microparticles. Molecules 2018, 23, 1886. [CrossRef]

16. Zu, Y.; Zhang, Y.; Wang, W.; Zhao, X.; Han, X.; Wang, K.; Ge, Y. Preparation and in vitro/ in vivo evaluation of resveratrol-loaded carboxymethyl chitosan nanoparticles. Drug Deliv. 2016, 23, 981-991. [CrossRef]

17. Ha, E.S.; Sim, W.Y.; Lee, S.K.; Jeong, J.S.; Kim, J.S.; Baek, I.; Choi, D.H.; Park, H.; Hwang, S.J.; Kim, M.S. Preparation and evaluation of resveratrol-loaded composite nanoparticles using a supercritical fluid technology for enhanced oral and skin delivery. Antioxidants 2019, 8, 554. [CrossRef] [PubMed]

18. Dhakar, N.K.; Matencio, A.; Caldera, F.; Argenziano, M.; Cavalli, R.; Dianzani, C.; Zanetti, M.; López-Nicolás, J.M.; Trotta, F. Comparative evaluation of solubility, cytotoxicity and photostability studies of resveratrol and oxyresveratrol loaded nanosponges. Pharmaceutics 2019, 11, 545. [CrossRef] [PubMed]

19. Shimojo, A.A.M.; Fernandes, A.R.V.; Ferreira, N.R.E.; Sanchez-Lopez, E.; Santana, M.H.A.; Souto, E.B. Evaluation of the influence of process parameters on the properties of resveratrol-loaded NLC using $2^{2}$ full factorial design. Antioxidants $2019,8,272$. [CrossRef] [PubMed]

20. Jadhav, P.; Bothiraja, C.; Pawar, A. Resveratrol-piperine loadedmixed micelles: Formulation, characterization, bioavailability, safety and in vitro anticancer activity. RSC Adv. 2016, 6, 112795-112805. [CrossRef]

21. Mamadou, G.; Charrueau, C.; Dairou, J.; Nzouzi, N.L.; Eto, B.; Ponchel, G. Increased intestinal permeation and modulation of presystemic metabolism of resveratrol formulated into self-emulsifying drug delivery systems. Int. J. Pharm. 2017, 521, 150-155. [CrossRef] [PubMed]

22. Balata, G.F.; Essa, E.A.; Shamardi, H.A.; Zaidan, S.H.; Abourehab, M.A.S. Self-emulsifying drug delivery system as a tool to improve solubility and bioavailability of resveratrol. Drug Des. Dev. Ther. 2016, 10, 117-128. [CrossRef]

23. Tang, H.; Xiang, S.; Li, X.; Zhou, J.; Kuang, C. Preparation and in vitro performance evaluation of resveratrol for oral selfmicroemulsion. PLoS ONE 2019, 14, e0214544. [CrossRef]

24. Kuk, D.H.; Ha, E.S.; Ha, D.H.; Sim, W.Y.; Lee, S.K.; Jeong, J.S.; Kim, J.S.; Baek, I.; Park, H.; Choi, D.H.; et al. Development of a resveratrol nanosuspension using the antisolvent precipitation method without solvent removal, based on a quality by design (QbD) approach. Pharmaceutics 2019, 11, 688. [CrossRef] [PubMed]

25. Alqarni, M.H.; Haq, N.; Alam, P.; Abdel-Kader, M.S.; Foudah, A.I.; Shakeel, F. Solubility data, Hansen solubility parameters and thermodynamic behavior of pterostilbene in some pure solvents and different (PEG-400 + water) cosolvent compositions. J. Mol. Liq. 2021, 331, 115700. [CrossRef]

26. Shakeel, F.; Haq, N.; Alanazi, F.K.; Alanazi, S.A.; Alsarra, I.A. Solubility of sinapic acid in various (carbitol + water) systems: Computational modeling and solution thermodynamics. J. Therm. Anal. Calorim. 2020, 142, 1437-1446. [CrossRef]

27. Sun, X.; Peng, B.; Yan, W. Measurement and correlation of solubility of trans-resveratrol in 11 solvents at $T=(278.2,288.2$. 298.2, 308.2, and 318.2) K. J. Chem. Thermodyn. 2008, 40, 735-738. [CrossRef]

28. Ha, E.S.; Kuk, D.H.; Kim, J.S.; Kim, M.S. Solubility of trans-resveratrol in Transcutol HP + water mixtures at different temperatures and its application to fabrication of nanosuspensions. J. Mol. Liq. 2019, 281, 344-351. [CrossRef]

29. Shakeel, F.; Haq, N.; Siddiqui, N.A.; Alanazi, F.K.; Alsarra, I.A. Solubility and thermodynamic behavior of vanillin in propane-1,2diol + water cosolvent mixtures at different temperatures. Food Chem. 2015, 188, 57-61. [CrossRef]

30. Jouyban-Gharamaleki, V.; Rahimpour, E.; Hemmati, S.; Martinez, F.; Jouyban, A. Mesalazine solubility in propylene glycol and water mixtures at various temperatures using a laser monitoring technique. J. Mol. Liq. 2020, 299, 112136. [CrossRef]

31. Osorio, I.M.; Martinez, F.; Delgado, D.R.; Jouyban, A.; Acree, W.E., Jr. Solubility of sulfacetamide in aqueous propylene glycol mixtures: Measurement, correlation, dissolution thermodynamics, preferential solvation and solute volumetric contribution at saturation. J. Mol. Liq. 2020, 297, 111889. [CrossRef]

32. Kao, Y.T.; Guo, X.; Yang, Y.; Liu, Z.; Hassanali, A.; Song, Q.H.; Wang, L.; Zhong, D. Ultrafast dynamics of nonequilibrium electron transfer in photoinduced redox cycle: Solvent mediation and conformation flexibility. J. Phys. Chem. B 2012, 116, 9130-9140. [CrossRef]

33. Van Krevelen, D.W.; Te Nijenhuis, K. Properties of Polymers: Their Correlation with Chemical Structure; Their Numerical Estimation and Prediction from Additive Group Contributions; Elsevier: Amsterdam, The Netherlands; Tokyo, Japan, 2009; p. 189.

34. Mohammad, M.A.; Alhalaweh, M.; Velaga, S.P. Hansen solubility parameter as a tool to predict cocrystal formation. Int. J. Pharm. 2011, 407, 63-71. [CrossRef] [PubMed]

35. Kitak, T.; Dumicic, A.; Planinsek, O.; Sibanc, R.; Srcic, S. Determination of solubility parameters of ibuprofen and ibuprofen lysinate. Molecules 2015, 20, 21549-21568. [CrossRef] [PubMed]

36. Greenhalgh, D.J.; Williams, A.C.; Timmins, P.; York, P. Solubility parameters as indictors of miscibility in solid dispersions. J. Pharm. Sci. 1999, 88, 1182-1190. [CrossRef] [PubMed]

37. Alanazi, A.; Alshehri, S.; Altamimi, M.; Shakeel, F. Solubility determination and three dimensional Hansen solubility parameters of gefitinib in different organic solvents: Experimental and computational approaches. J. Mol. Liq. 2020, 299, 112211. [CrossRef] 
38. Apelblat, A.; Manzurola, E. Solubilities of o-acetylsalicylic, 4-aminosalicylic, 3,5-dinitrosalicylic and p-toluic acid and magnesiumDL-aspartate in water from $\mathrm{T}=(278-348) \mathrm{K} . \mathrm{J}$. Chem. Thermodyn. 1999, 31, 85-91. [CrossRef]

39. Manzurola, E.; Apelblat, A. Solubilities of L-glutamic acid, 3-nitrobenzoic acid, acetylsalicylic, p-toluic acid, calcium-L-lactate, calcium gluconate, magnesium-DL-aspartate, and magnesium-L-lactate in water. J. Chem. Thermodyn. 2002, 34, 1127-1136. [CrossRef]

40. Ksiazczak, A.; Moorthi, K.; Nagata, I. Solid_solid transition and solubility of even n-alkanes. Fluid Phase Equilibria 1994, 95, 15-29. [CrossRef]

41. Tong, Y.; Wang, Z.; Yang, E.; Pan, B.; Jiang, J.; Dang, P.; Wei, H. Determination and correlation of solubility and solution thermodynamics of ethenzamide in different pure solvents. Fluid Phase Equilibria 2016, 427, 549-556. [CrossRef]

42. Yalkowsky, S.H.; Roseman, T.J. Solubilization of drugs by cosolvents. In Techniques of Solubilization of Drugs; Yalkowsky, S.H., Ed.; Marcel Dekker Inc.: New York, NY, USA, 1981; pp. 91-134.

43. Jouyban, A. Review of the cosolvency models for predicting solubility of drugs in water-cosolvent mixtures. J. Pharm. Pharm. Sci. 2008, 11, 32-58. [CrossRef] [PubMed]

44. Sardari, F.; Jouyban, A. Solubility of nifedipine in ethanol + water and propylene glycol + water mixtures at 293.2 to $313.2 \mathrm{~K}$. Ind. Eng. Chem. Res. 2013, 52, 14353-14358. [CrossRef]

45. Sotomayor, R.G.; Holguín, A.R.; Romdhani, A.; Martínez, F.; Jouyban, A. Solution thermodynamics of piroxicam in some ethanol + water mixtures and correlation with the Jouyban-Acree Model. J. Sol. Chem. 2013, 42, 358-371. [CrossRef]

46. Ryde, U. A fundamental view of enthalpy-entropy compensation. MedChem Comm 2014, 5, 1324-1336. [CrossRef]

47. Sharp, K. Enthalpy-entropy compensation: Fact or artifact. Protein Sci. 2001, 10, 661-667. [CrossRef]

48. Pan, A.; Biswas, T.; Rakshit, A.K.; Moulik, S.P. Enthalpy-entropy compensation (EEC) effect: A revisit. J. Phys. Chem. B 2015, 119, 15876-15884. [CrossRef]

49. Alshehri, S.; Shakeel, F. Solubility determination, various solubility parameters and solution thermodynamics of sunitinib malate in some cosolvents, water and various (Transcutol + water) mixtures. J. Mol. Liq. 2020, 307, 112970. [CrossRef]

50. Shakeel, F.; Haq, N.; Alsarra, I.A.; Alshehri, S. Solubility, Hansen solubility parameters and thermodynamic behavior of emtricitabine in various (polyethylene glycol-400 + water) mixtures: Computational modeling and thermodynamics. Molecules 2020, 25, 1559. [CrossRef]

51. Bellissent-Funel, M.C.; Hassanali, A.; Havenith, M.; Henchman, R.; Pohl, P.; Sterpone, F.; van der Spoel, D.; Xu, Y.; Garcia, A.E. Water determines the structure and dynamics of proteins. Chem. Rev. 2016, 116, 7673-7697. [CrossRef]

52. Higuchi, T.; Connors, K.A. Phase-solubility techniques. Adv. Anal. Chem. Instrum. 1965, 4, 117-122.

53. Singh, G.; Pai, R.S. A rapid reversed-phase HPLC method for analysis of trans-resveratrol in PLGA nanoparticulate formulation. ISRN Chromatogr. 2014, 2014, 248635. [CrossRef]

54. Wan, Y.; He, H.; Huang, Z.; Zhang, P.; Sha, J.; Li, T.; Ren, B. Solubility, thermodynamic modeling and Hansen solubility parameter of 5-norbornene-2,3-dicarboximide in three binary solvents (methanol, ethanol, ethyl acetate + DMF) from $278.15 \mathrm{~K}$ to $323.15 \mathrm{~K}$. J. Mol. Liq. 2020, 300, 112097. [CrossRef]

55. Zhu, Q.N.; Wang, Q.; Hu, Y.B.; Abliz, X. Practical determination of the solubility parameters of 1-alkyl-3-methylimidazolium bromide ([CnClim] Br, $\mathrm{n}=5,6,7,8)$ ionic liquids by inverse gas chromatography and the Hansen solubility parameter. Molecules 2019, 24, 1346. [CrossRef]

56. Altamimi, M.; Haq, N.; Alshehri, S.; Qamar, W.; Shakeel, F. Enhanced skin permeation of hydrocortisone using nanoemulsion as potential vehicle. ChemistrySelect 2019, 4, 10084-10091. [CrossRef]

57. Babaei, M.; Shayanfar, A.; Rahimpour, E.; Barzegar-Jalali, M.; Martínez, F.; Jouyban, A. Solubility of bosentan in \{propylene glycol + water\} mixtures at various temperatures: Experimental data and mathematical modeling. Phys. Chem. Liq. 2019, 57, 338-348. [CrossRef]

58. Jouyban, A.; Chan, H.K.; Chew, N.Y.; Khoubnasabiafari, N.; Acree, W.E., Jr. Solubility prediction of paracetamol in binary and ternary solvent mixtures using Jouyban-Acree model. Chem. Pharm. Bull. 2006, 54, 428-431. [CrossRef]

59. Jouyban, A.; Acree, W.E., Jr. In silico prediction of drug solubility in water-ethanol mixtures using Jouyban-Acree model. J. Pharm. Pharm. Sci. 2006, 9, 262-269.

60. Ruidiaz, M.A.; Delgado, D.R.; Martínez, F.; Marcus, Y. Solubility and preferential solvation of indomethacin in 1,4-dioxane + water solvent mixtures. Fluid Phase Equilibria 2010, 299, 259-265. [CrossRef]

61. Krug, R.R.; Hunter, W.G.; Grieger, R.S. Enthalpy-entropy compensation. 2. Separation of the chemical from the statistic effect. J. Phys. Chem. 1976, 80, 2341-2351. [CrossRef]

62. Holguín, A.R.; Rodríguez, G.A.; Cristancho, D.M.; Delgado, D.R.; Martínez, F. Solution thermodynamics of indomethacin in propylene glycol + water mixtures. Fluid Phase Equilibria 2012, 314, 134-139. [CrossRef] 